\section{$\underset{\substack{\text { hommes } \\ \text { \& migrations }}}{ }$}

\section{Hommes \& migrations}

Revue française de référence sur les dynamiques

migratoires

$1314 \mid 2016$

Migrations chinoises et générations

\title{
Li Ma (dir.), Les Travailleurs chinois dans la Première
}

Guerre mondiale

CNRS éd., 2012, 560 p., $39 €$

\section{Hélène Le Bail}

\section{(2) OpenEdition}

Journals

Édition électronique

URL : http://journals.openedition.org/hommesmigrations/3674

DOI : 10.4000/hommesmigrations.3674

ISSN : 2262-3353

Éditeur

Musée national de l'histoire de l'immigration

Édition imprimée

Date de publication : 1 avril 2016

Pagination : 174-175

ISBN : 978-2-919040-35-3

ISSN : 1142-852X

Référence électronique

Hélène Le Bail, « Li Ma (dir.), Les Travailleurs chinois dans la Première Guerre mondiale », Hommes \& migrations [En ligne], 1314 | 2016, mis en ligne le 19 septembre 2016, consulté le 23 septembre 2020. URL : http://journals.openedition.org/hommesmigrations/3674; DOI : https://doi.org/10.4000/ hommesmigrations.3674 


\section{LIVRES}

Li Ma (dir.)

Les Travailleurs chinois dans

la Première Guerre mondiale

Paris, CNRS éd., 2012, 560 p., $39 €$

Le livre dirigé par Li Ma et publié en 2012 est devenu l'ouvrage de référence sur la participation de la Chine à la Guerre de 19141918. Par l'envoi de quelque 140000 travailleurs en France et 200000 en Russie, la Chine contribua à l'effort de guerre puis à la reconstruction, aux côtés des Alliés, entre 1916 et 1922. L'ouvrage retrace l'histoire de ces travailleurs chinois en France, depuis leur recrutement jusqu'au retour en Chine après la guerre. Certains restèrent en France où ils avaient commencé à construire leur vie. Aujourd'hui, les cimetières militaires sont le miroir de cette page d'histoire. Li Ma est souvent venue se promener et observer les tombes de ces Chinois, par exemple dans le cimetière de Noyellessur-Mer tout proche de l'université Littoral Côte d'Opale où elle enseigne.

L'ouvrage rassemble, à travers 23 contributions, la quasi totalité des travaux sur cet épisode peu connu de la Grande Guerre : travaux de chercheurs français, chinois, américains, anglais et belges, mais aussi de représentants associatifs et de descendants de ces travailleurs. Le premier contrat de recrutement fut conclu par la France en 1916 (sous le nom de "Mission Truptil"), rapidement imitée par les Britanniques (on parle en anglais de Chinese Labor
Corps). Les contrats passés indiquaient l'impossibilité de participer aux activités de guerre, la distance minimum au front, ainsi que le temps de travail, le salaire, etc. Sont ensuite décrit les lieux et conditions du départ des travailleurs volontaires ainsi que celles de leur transport "top secret" via le Canada.

Les Chinois recrutés par la France furent dispersés dans un grand nombre de lieux à travers la France. Plusieurs chapitres décrivent les conditions de vie dans les camps et sur les lieux de travail dans le Nord, en Picardie, mais aussi en Normandie, en Bretagne, dans le Var ou à la Rochelle. Y sont évoqués la fréquence des maltraitances et la généralisation du racisme. Toutefois, pour certains le séjour en France fut l'occasion d'une alphabétisation ou d'une formation, voire d'une politisation grâce à la rencontre avec des étudiants chinois.

D'autres chapitres s'intéressent aux diverses formes de témoignages laissés par ces travailleurs chinois : graffitis sur les murs des carrières, "art des tranchées" (objets de style chinois réalisés avec des matériaux recyclés), témoignages écrits par les travailleurs ou leurs descendants. À la fin de la guerre, 3 ooo environs seraient restés en Europe et ont grossi les petites communautés d'étudiants et d'artisans chinois. Certains s'installent à Paris où ils retrouvent des personnes venant des mêmes régions de Chine, dont celle de Wenzhou qui est restée jusqu'à aujourd'hui une des principales régions d'origine des Chinois de France. Toutefois, comme le décrit en conclusion l'historienne Marianne Bastid-Bruguière, la plupart de ces travail- 
leurs rentrèrent en Chine, où la réinsertion après plusieurs années passées en France fut parfois difficile, parfois facili- tée par l'acquisition d'un savoir faire ou par leur expérience du syndicalisme.

Hélène le Bail

\section{Chahla-Chafiq \\ Demande au Miroir \\ Paris, L'Âge d'Homme, 2015,224 P., $19 €$}

te regard est omnipré sent dans le premier roman en français de Ehahla Chafig, écrivain et sociologue iranienne exilée en France depuis 1983, reconnue pour ses travaux sur fistamisme(1). Le personnage central de Demande au miroir, Guita Salim, regarde-la vie de sa fenêtre. "Entre la fenêtre et levoir, ilyatoujours un écart", écrit Forough Farrokhzâd, poétesse per sane qui illumina les années 1950-1960, dont la poésie traverse ce roman. Ado lescente, dans une ruelle de Téhéran, la jeune héröne entrevoit devant elle le salon animé de sa mystérieuse et fas einante voisine, Elaheh, "divine déesse" en persan. Sa voisine est romancière. "Les romancierset les poìtes profitaient tout autant queles fous du village d'une indulgence sans bornes", fait dire Chahla Ehafiq àson personnage. Mariée, Guita eontinue de rester des heures derrière sa fenêtre, le corps lourd d'un enfant ì naitre. Un deuil intime la plonge dans un monde froid et gluant. Elle ne par ticipera pas ì la Révolution qui amène Khomeiny au pouvoir et s'enfonce dans la mort, comme-son pays où sévit une répression brutale et meurent les jeunes hommes envoyés à la guerre eontrel'Irak.

te titre évoque til te Miroir brisé de Forough Farrokhzâd, dans lequel une femme se fait belle devant son miroir en souvenir de son amour perdu, qui, hélas, n'est pas là pour voir dans ses yeux noirs "le reflet de son propre visage"? Guita a le ceur brisé quand ta mort frappe à nouveau sa famille, aulendemain de la Révolution. Elle se décide enfin ì changer de fenêtre et s'exile ì Paris avec son mari. "Partir en France et perdre ses attaches ne l'émou vaient pas plus", écrit Chahla Chaffa. clle accepte doucement de décou vrir cette ville et cette langue dont les auteurs du XIXe siècle furent les fenêtres vers l'ailleurs de son adoles eence iranienne. À Paris, une nouvelle lucarne s'ouvre qu'elle n'avait pasima ginée. I'Internet. Nous sommes dans les années 1990. Guita, divorcée, a un nouveau métier et semble avoir trouvé savoie.

te roman commence sur cette-interrogation, quon devine être celle de l'au teur le passé passe $t$ il? Peut on tour ner le dos à la douleur de la disparition deceux qu'on aime, d'un pays telqu'on taconnulet de ses rêves? Demande au Aliroir nous plonge dans la vie de plu sieurs exilés, intellectuels et artistes iraniens, qui aimerait continuer ì eréer, malgré les blessures et désillu 